\title{
Literatura e historia oral: la vida de los chicleros quintanarroenses durante el cardenismo
}

\section{Luz del Carmen Vallarta Vélez}

La literatura, además de ser útil como una forma de expresión sociocultural que da una visión particular de ła realidad, permite por medio de esta cualidad artística la percepción sutil de las relaciones sociales y de las que el hombre establece con la naturaleza. Nos permite también, como historiadores, captar tendencias culturales, momentos históricos, actitudes y posiciones ideológicas.

La relación entre la literatura y la historia tiene dos sentidos y una serie de manifestaciones complejas, que el historiador sistematiza, pero, y es un gran pero, que no podría detectar si no abriera y "disciplinara" su sensibilidad hacia esta manifestación artística.

Entonces, tenemos que el hilo en el cual engarzaremos la historia oral es la literatura. Nos interesa, en general, hacer una reconstrucción de las características que el cardenismo tuvo en Quintana Roo. En particular, dos temas que no han sido lo suficientemente trabajados: la producción chiclera después de la crisis mundial de 1929 y el análisis de aquellos autores que escribieron sobre y en Quintana Roo. Para el caso concreto de este trabajo, los dos temas se vincularon estrechamente.

Se parte de la idea de que las novelas realistas con tendencias sociales pueden o no llegar a considerarse como fuentes históricas por la forma en que reflejan la realidad al describir situaciones y personajes. En caso de un resultado positivo, los hechos históricos que se reflejan en ella son per se datos que el investigador puede utilizar directamente. Pero si el resultado fuese negativo, el hecho de no ser una fuente histórica fidedigna no invalida la importancia histórica general de la novela. Esta diferenciación es relevante ya que nos permite analizar a fondo el contexto histórico social en que la obra se produjo.

Tomando como base las proposiciones teórico-metodológicas de John Rutherford ${ }^{1}$ y la comparación de la obra con la historia oral, se puede afirmar que la novela Claudio Martín, vida de un chiclero, escrita y publicada por Luis Rosado Vega en 1938, no puede ser utilizada como fuente histórica por sí misma. ${ }^{2}$

Autores como J. S. Brushwood y Adalbert Dessau establecen una relación entre la historia de México y la forma en que se plasma en la literatura. Pero es John Rutherford quien explicitamente se plantea el problema de la novela como fuente histórica. proponiendo además una metodología concreta para acercarse al binomio historia-literatura. Véase J. S. Brushwood, México en su novela, México, FCE, 1973 (Breviario, 230); Adalbert Dessau, La novela de la Revolución mexicana, Mexico, FCE, 1972 (Breviario, 117); John Rutherford, La sociedad mexicana durante la revolución, México, Ed. El Caballite, 1978.

: Luis Rosado Vega nació en Chemax, Yucatán, en 1873 y murió en Mérida en 1958. Fue poeta. periodista y novelista, el único trabajo que llevó a cabo fuera de Yucatán fue dirigir el Ateneo de Ciencias y Artes de Tlaxcala. Trabajó en el Colegio de Normalistas de Mérida y fue director del Museo Histórico y Arqueológico 
La reconstrucción de la historia de Quintana Roo está apenas haciéndose y uno de los caminos que se ha tomado es el de la historia oral. La mayoria de la información general que aquí se presenta, es el resultado de entrevistas a personas que vivieron la época del cardenismo en Quintana Roo y que además fueron chicleros y caoberos durante esos años.

Las ficciones literarias que Rosado Vega incluye en la obra, no sirven como datos históricos, porque falsean la realidad histórico-social de la producción chiclera de Quintana Roo. El falseamiento en la novela es válido, pero cuando se entra al ámbito de la historia se tiene que medir por medio del contraste que la novela presenta respecto a hechos históricos reales y concretos, que en este caso son las vivencias particulares de los informantes.

En el caso de Claudio Martín el qué se dice y el cómo se dice no nos son útiles como hechos históricos particulares, pero el cuándo y el quién la escribe tiene una importancia especial para la historia concreta de Quintana Roo. El momento histórico en el que se escribió la novela, las razones para escribirla y el que no puede ser considerada a su vez como fuente histórica, son datos históricos concretos que nos permiten entender las características y la importancia ideológica, política, social y económica que tuvo durante el cardenismo en Quintana Roo.

La reconstrucción que hace Rosado Vega de la vida de los chicleros está falseada en varios momentos con el propósito ideológico de dar todo el "crédito revolucionario" al régimen de Cárdenas. La novela además fue concebida usando lo que Rutherford llama la atmósfera del periodo durante el cual fue escrita: el cardenismo. El autor pone en la trama de la novela todos aquellos elementos que en la época se consideraron como claves para integrar el territorio de Quintana Roo al todo nacional. Esto no lo lleva a cabó en

de Yucatán. Como periodista y literato colaboró en el Diario Yucateco, El Ateneo de Mérida, Revista de Revistas, Revista de Mérida y en diversos diarios de Cuba y México. Famoso por haber compuesto "Peregrina", canción escrita para Alma Reed por encargo de Felipe Carrillo Puerto; Ricardo Palmerin puso la música. Los primeros libros de poemas que publicó entre 1902 y 1907 acusan fuertes influencias de Ruben Dario, Santos Chocano y Amado Nervo. Su poemario Libro del ensuefio y del dolor de 1907 le dio sitio entre los poetas modernistas. Su primera novela Maria y Clemencia (1912) presenta tendencias románticas y realistas, estilos presentes junto con el naturalismo en otras de sus novelas. Según Esquivel Pren toda la prosa de Rosado Vega "acude a cumplir una misión social, a satisfacer una bella idea o a combatir una llaga antirrevolucionaria. Porque Rosado Vega, lo mismo en el campo de las letras que en el terreno de lo social, siempre ha sido un idealista revolucionario en su sentido más puro, más elevado y más digno". Véase José Esquivel Pren. "Historia critica de la literatura", en Enciclopedia Yucatanense. Mérida, Ed. del Gobierno del Estado de Yucatán, 1977, p. 484-492 y 661-664.

Estas entrevistas son parte del trabajo de investigación que sobre la formación de la ciudad de Chetumal y la definición de la frontera México-Belice se llevó a cabo de abril de 1985 a agosto de 1987 , como parte del equipo de investigación del CIESAs Sureste, dirigido por el doctor Andrés Fábregas Puig. El material que se presenta es resultado de las entrevistas que se tuvieron con don Luis Reinhardt MacLiberty, don Aurelio Aranda(+), don Luis Lizárraga, don Nicolás Carrillo, dota Lumanda Barquet y doña Florencia Reyes.

+ Rutherford (p. 21) plantea el problema del falseamiento y la forma en que este se puede evaluar. El enfoque literario de la historia social depende de un examen cuidadoso de las muchas influencias que puede haber sufrido cada autor, es necesario localizar las partes de sus textos donde es más probable que haya falsea- 
forma directa, sino a través de la presentación de situaciones negativas que supuestamente el cardenismo vino a solucionar."

La concepción particular de Rosado Vega sobre la Revolución mexicana y la novela en sí misma, son expresiones ideológicas y políticas de la forma en que el Estado nacional definió e implantó su poder y supremacia en una zona fronteriza del país, región que se caracterizó hasta antes de 1934 por las estrechas relaciones que tuvo con Belice y el Caribe, así como por el distanciamiento geográfico, económico y cultural con el resto de México.

Por otro lado, los testimonios de los informantes son el reflejo de una realidad concreta que individuos concretos tuvieron que vivir para contraponer, aceptar, modificar o decantar estas políticas particulares del Estado nacional. El contraste entre la forma literaria que es la novela con toda su carga ideológica y los testimonios de los trabajadores de la selva, nos permiten vislumbrar la complejidad de esta realidad histórico-social.

Así entonces el diálogo entre la historia oral y la literatura, entre la ciencia y el arte, nos aporta una rica información no sólo sobre la historia de una región, sino también sobre sus características políticas, económicas y socioculturales. La ponencia pretende demostrar la riqueza de la relación.

La presencia de Rosado Vega en Quintana Roo está relacionada estrechamente al periodo cardenista. Escribió tres obras sobre la entidad, dos de las cuales se consideran lo mejor de su producción en este género, además de novela y poesía.

Pasó cuatro temporadas de seis meses cada una en Quintana Roo, todas durante el mandato del general Rafael Melgar. La primera vez llegó en 1937 como director y organizador de la Expedición Científica Mexicana, la cual tenía como propósito hacer un estudio exhaustivo de las condiciones físicas y sociales del territorio de Quintana Roo.

Como resultado de este primer viaje, produjo El poema de la selva trágica, poema épico y dramático, desarrollado en catorce largas poesias ${ }^{6}$ que corresponden a las catorce jornadas que el autor pasó entre los chicleros y caoberos como miembro de la Expedición Científica. El objetivo del libro es denunciar las vejaciones que sufren los trabajadores, los cuales son explotados por contratistas extranjeros.

La segunda estancia de Rosado Vega fue en 1938 y después de ella publica la novela que aquí nos ocupa, Claudio Martín, vida de

miento, especificando qué clase de falseamiento puede esperarse. Para Rutherford el falseamiento es una variación individual del consenso social, esta variación puede presentar distintos matices y grados, desde ser una variación sutil hasta la desfiguración de un hecho. Lo primero se puede corregir con fines historiograficos y en sí mismo puede dar información histórica y sociológica de forma directa, pero la desfiguración presenta poca validez históricosocial directa. Aquí es donde hay que plantear un nivel distinto de análisis: el conjunto de la novela como dato histórico en sí.

I Ibidem, p. 86. El subrayado es del autor.

${ }^{6}$ Los nombres de los poemas que lo componen (Esquivel Pren, op. cit., p. 490), nos dan una idea de la temática: "La selva trágica", "La maraña", "Los hijos de la tierra", "El habitat", "La muerte en siesta", "La tormenta", "Delirante nox", "La caravana", "El hato", "Isla Catalina", "El árbol de la sangre blanca", "La abuela caoba", "Conminación" y "A la luz del alba". 
un chiclero, ${ }^{7}$ donde pinta el drama de los chicleros explotados hasta la muerte.

La tercera y cuarta estancias en el territorio fueron entre 1939 y 1940, el resultado es un ensayo histórico de 445 páginas, ilustrado con fotografías y mapas, de la Expedición Científica Mexicana. El libro es una apología del régimen cardenista y de la gubernatura de Melgar. ${ }^{8}$

La temática de esta obra es muy variada, va desde descripciones de la geografia del territorio hasta una reconstrucción de su historia prehispánica, pasando por la del asentamiento inglés de Belice, las relaciones diplomáticas con Inglaterra y Guatemala, supersticiones y leyendas; la división etnográfica del territorio, la educación, el problema del agua, los perimetros libres y el movimiento cooperativista organizado y promovido por Melgar como parte de la política cardenista de organización del trabajo.

En la novela, Rosado Vega hace referencia a una serie de situaciones históricas que van desde la guerra de Castas de 1847 hasta los años treinta del presente siglo. El propósito de mencionar todos estos hechos históricos es el de dar al lector un telón de fondo, a partir del cual se concluya la importancia de las reinvindicaciones revolucionarias de la época de Cárdenas.

El argumento de la novela sigue dos líneas, por un lado es una historia de amores fallidos y por el otro es la historia de las injusticias sociales que viven los chicleros. Una trama pasional y otra laboral. Estas dos lineas se trenzan de tảl forma que el héroe de la novela, Claudio Martín es el actor principal de ambas. El es el protagonista de la historia de amor y al mismo tiempo el autor pone en su boca la mayoría de los ideales revolucionarios que Claudio comparte con otro personaje, un chiclero viejo y experimentado llamado Cachimba.

Claudio Martín es un muchacho cozumeleño que a la muerte de su padre decide ir a probar fortuna a la zona de Payo Obispo-Río Hondo. Lo acompañan su hermana Lucía y su mejor amigo, Pepe Antonio, quien desde pequeño, está enamorado de Lucía, chiqui-

\footnotetext{
7 Luis Rosado Vega, Claudio Martín, vida de un chiclero, México, Ediciones SCOP, 1938. Características de la obra: Aun cuando Claudio Martín es una novela con caracteristicas realistas y naturalistas, el argumento procede directamente del romanticismo. Los amores fallidos, caracteristicas tipicas de esa corriente, aquí se frustran no por las razones que este estilo usaria, como la religión, la costumbre o la imposibilidad moral; aqui lo que impide que se reúnan los amantes son las fuerzas sociales (realismo). Rosado Vega describe con lujo de detalles los sentimientos de sus personajes, pero también, caracteristica que lo acerca al realismo, nos describe las motivaciones psicológicas del personaje. Como parte de una tendencia naturalista, el autor pone a la Vida, junto con el Destino, la Providencia, la Fortuna, Dios y el Diablo, como aquellas entidades que marcan la existencia de los hombres y la determinan. Otro elemento naturalista en la obra son las sórdidas descripciones.

${ }^{8}$ Luis Rosado Vega, Un pueblo y un hombre, México, Ed. Mijares, 1940.

' Las tres obras de Rosado Vega sobre Quintana Roo son esenciales, ya que el material hemerográfico, documental y bibliografico sobre la región apenas se está concentrando en el estado. El material estaba desperdigado por Mérida, Campeche, México y Belice. Los trabajos publicados durante el periodo cardenista en Quintana Roo son relativamente pocos, por eso la obra de Rosado Vega es importante y más relevante es todavia el analizarla para definir su valor como fuente histórica primaria y secundaria.
} 
lla coqueta que ya de mayor será el origen de todas las desventuras de Claudio y Pepe Antonio.

Se enganchan con una companía estadunidense que se dedica a la extracción de chicle y de caoba; la compañia tiene concesión del gobierno mexicano para explotar estas materias primas en la ribera del río Hondo. Su sede está en el puerto de Belice. Ellos se contratan para el trabajo del chicle y el padre de la novia de Claudio, Maria del Pilar, se engancha para el corte de caoba.

El contratista general y capataz de la compañía, don Casiano Menéndez, queda prendado de Lucía y decide a toda costa hacerla su amante. Claudio y Pepe Antonio, que se dan cuenta de las aviesas intenciones del contratista, se proponen hacer lo imposible por evitar que perpetre su crimen. Pero el destino y Lucía, ambiciosa y ligera de cascos, impedirán que Claudio y su amigo cumplan su propósito. Cuando llegan a Payo Obispo, Lucía se niega a ir a vivir con Claudio al hato chiclero, al cual sólo es posible llegar después de navegar por el río Hondo y cruzar la selva a lomo de mula.

Lucia se queda en Payo Obispo bajo la custodia de una sirvienta, mujer todavia más pobre que ellos y que cree que la muchacha es buena. Claudio y Pepe Antonio se van al mismo hato chiclero. El suegro y la novia se instalan en un campamento caobero a corta distancia.

Don Casiano no pierde tiempo para conquistar los favores de Lucia. Contrata a una alcahueta para que le vaya trabajando a la muchacha, quien se deja querer. El contratista le regala joyas y ropa que compra en la tienda de un turco, que también aprecia los encantos de la hermana de Claudio.

En el hato Claudio intuye lo que sucederá con su hermana. Un día, haciéndose el enfermo, regresa de improviso a Payo Obispo para encontrarse con que Lucia está a punto de caer en las garras del libidinoso y obeso contratista. Después de pasar unos días en la ciudad finge regresar al hato chiclero, para volver a Payo Obispo sin que nadie lo note:

Aprovechando, la supuesta ausencia de Claudio, Lucía acepta ir con el contratista a un baile de mala muerte. Claudio los espia y después de que los futuros amantes (porque ya la convenció) quedan de encontrarse al día siguiente, Lucía regresa a su casa y el contratista va en busca de una prostituta. Claudio lo espera y lo asesina.

Los vecinos se dan cuenta del crimen y Claudio tiene que huir por el río a Belice. Se topa con unos negros a los cuales ayuda a contrabandear chicle a cambio de que lo pasen otra vez del lado mexicano del río y lo dejen en un lugar seguro. Cada uno cumple con su parte del trato y Claudio regresa a Quintana Roo, donde un grupo de mayas lo protegen.

Mientras tanto hay un despliegue de fuerzas policiacas para cazar a Claudio. Su crimen no puede quedar impune, pues a quien mató no fue a un simple ser humano sino al contratista y capataz de una fuerte compañia extranjera.

Sus compañeros chicleros están dispuestos a apoyarlo, especialmente Pepe Antonio que sabe y comparte el intenso sufrimiento de Claudio. Al llegar al hato a refugiarse, recibe la noticia de que Maria del Pilar está muy grave. Tiene que esperar varios días para 
irla a ver porque hay una patrulla merodeando por el rumbo.

Durante ese lapso de tiempo se entera de que Lucía murió en circunstancias misteriosas. El tendero turco, al conocer el asesinato del contratista, quiere conquistar a la muchacha. Pero el turco tiene una negra beliceña como amante, la cual al darse cuenta de que está a punto de perder el galán, manda traer de Belice a su hermano, experto en magia negra. Organizan una sesión para embrujar a Lucia, que muere al día siguiente.

Las desgracias no terminan ahí. Cuando Claudio puede ir a ver a su novia, llega sólo para enterarse de que María del Pilar acaba de ser enterrada, victima de una tuberculosis mal atendida.

Regresa al hato con su inseparable amigo. Le pide que para aliviar sus penas lo acompañe a chiclear al día siguiente. Claudio sube a un chicozapote y después de entonar una canción popular entre los chicleros, corta él mismo su lazadera, cayendo de espaldas y muriendo al estrellarse en el piso diez metros abajo. Tiempo después también muere su pretenso suegro y de Pepe Antonio no se sabe nada durante años, hasta que un día llega la noticia de que murió en un naufragio.

Aun cuando la novela no se refiere a ningún episodio revolucionario ni relata las experiencias personales de alguien que la haya vivido, puede considerarse dentro del género de las novelas de la Revolución mexicana, ya que el propósito principal del autor es reinvindicarla directamente.

Esto lo logra Rosado Vega por medio de los personajes que anhelan que algún día se les haga justicia. El sacrificio de sus vidas no fue en vano ya que el cardenismo llegó al territorio y mejoró la situación de los trabajadores de la caoba y del chicle.

Hemos visto que dos son los hilos que guían la novela: la historia de amor y la búsqueda de justicia social. El primer lugar lo ocupa la historia de un romance imposible, pero poco a poco esta intención se supedita a un propósito más importante, el demostrar las pésimas condiciones de vida y trabajo de chicleros y caoberos antes del cardenismo.

Mezclando los tiempos históricos y literarios; Rosado Vega dice que cuando Claudio Martín se suicidó ya había comenzado la $\mathrm{Re}$ volución mexicana en el norte del pais; revolución que en un primer momento tuvo como propósito derrocar al dictador y no propugnar por un régimen de liberación para "las clases sufridas de la nación". Débiles eran los cimientos de esa revolución política, que al no plantearse cuestiones sociales se derrumbó. Para él, Francisco I. Madero fue "aquel noble visionario, que sello con sangre muy generosa la abyecta traición de que fue víctima".

Hay para Rosado Vega una segunda revolución, aquella que surge también "en el norte" y en la que ya no se dan componendas políticas. Esta nueva revolución poco a poco avanza sobre el país. Pero el punto culminante de la revolución en general es el cardenismo, régimen que fue de especial importancia para Quintana Roo, ya que ahí no se habia dado directamente ninguna reinvindicación revolucionaria hasta que Cárdenas manda como gobernador del territorio al general Melgar. 
Rosado Vega establece un símil entre la Revolución y el proceso de "evolución" de una nación:

Sin embargo, y sea como sea, el proceso de evolución, se ha impuesto, y ese proceso a la hora de narrar el romance triste y significativo de Claudio Martín, es un hecho. En las vastas selvas del territorio quintanarroense, comienza aún, es cierto, pero comienza en firme [...] Mandatarios de más limpia conciencia revolucionaria lo han iniciado y tan nuevamente, que puede decirse que ese paso hacia adelante imprime sus huellas sobre la miseria y la sangre, calientes aún de lo que fuera hasta ayer el trabajo de aquellos hombres del chicle y de la caoba [...] Ya en aquellas hermosas selvas semiafricanas, los trabajadores no están a completa merced de los magnates del oro; ya no los atormenta el fuete del contratista. Venden como suyo lo que arrebatan a la selva. Sin embargo, es el comienzo de esas modalidades que implican o implicarán una sólida transformación. Por lo mismo, es cuando más afán habrá de ponerse para ir afirmando esa vida que apenas se abre a la luz."

Es durante el cardenismo cuando el trabajador del chicle "vende como suyo lo que arrebata a la selva"; en esta etapa política se organizan cooperativas para la extracción chiclera y maderera y son los propios trabajadores los que venden la producción a las compañias inglesas y estadunidenses en Belice.

Claudio y Cachimba son los dos personajes que sirven a Rosado Vega para hacer patentes sus ideales revolucionarios. El autor utiliza a Cachimba para expresar hasta sus últimas consecuencias toda su concepción sobre la Revolución. La única función de este personaje es ser la "conciencia del trabajador". Rosado Vega pone también en su boca la idea de la esterilidad del trabajo que llevan a cabo, donde dejan su vida y su sangre ¿para qué?...

Para enriquecer, decia apretando los puños, a unos señores extranjeros que ni siquiera conocían, que allá en la lejana metrópoli nadaban en toda clase de abundancias, apilando tesoros cuantiosos, en oficinas de gran suntuosidad, con cientos de empleados que despachaban pastillitas olorosas a fin de que señoritos y señoritas fifis de las ciudades del mundo movieran las quijadas placenteramente, mientras ellos, los trabajadores, reventaban que era un gusto. ${ }^{12}$

Para relacionar literatura e historia oral, se dividieron en tres bloques los distintos puntos de contraste entre la novela y el resultado de las entrevistas de historia oral:

1. Condiciones de vida de los trabajadores en los hatos.

2. Relaciones obrero-patronales y organización del trabajo para la extracción del chicle.

3. Payo Obispo y las relaciones con Belice.

Igual que otros autores de la época como Moisés Sáenz y Ramón Beteta, ${ }^{13}$ escribe Rosado Vega sobre la selva y la extracción

1 Ibidem. p. 257-258.

12 Ibidem, p. 112.

1.3 Ramón Beteta, Tierra del chicle, México, México Nuevo, 1951; Moisés Sáenz, México integro. Lima. Torres Aguirre, 1939. 
del chicle y la madera desde el punto de vista de hombres con una cultura urbana. Juzgan la vida cotidiana en la selva desde sus parámetros de bienestar y comodidad. Para cualquiera que ha crecido rodeado de asfalto, la experiencia de moverse en ese medio ambiente natural puede ser terrorífica.

De ahí que el autor base buena parte de la impresión que debe causar su novela en descripciones muy sórdidas sobre la manera en que el trabajo se desarrollaba, como un punto importante de contraste respecto a los testimonios de la gente entrevistada. La respuesta, que varía en intensidad, detalles y énfasis, cuando se les pregunta su opinión sobre el tiempo que trabajaron como chicleros y caoberos, es que fue ésta la época más libre y bella de sus vidas.

Si algo hay que criticarle a Rosado Vega es que pocas veces a lo largo de la novela asume que tanto chicleros como caoberos tenían ya de antiguo una cultura con la cual podían sortear, aceptar y ver como perfectamente naturales los supuestos peligros y las contingencias de su relación con la naturaleza. Cultura que queda plasmada en cada entrevista a través de los relatos de sus vivencias cotidianas: el tigre, la nauyaca, el sisimite eran los enemigos contra los que había que "pelear" todos los días, pero también eran los "compañeros" del solitario vagabundeo del chiclero por la "montaña".

En general el autor pone a las mujeres como lo más bajo en la escala humana. Por más que los requerimientos del argumento de la novela hicieran necesario que Lucia fuera excesivamente coqueta, resulta que sólo la sirvienta vieja que la cuidaba y María del Pilar no eran mujeres de la "mala vida". Según Rosado, todas las mujeres que iban con los hombres a la selva cumplian dos funciones: cocinar y prostituirse. La familia como núcleo social no aparece en la obra y, si hay niños, son los hijos de eternas madres abandonadas.

Lo anterior contrasta notablemente con los testimonios que se han recogido. En los campamentos y hatos se daba toda una organización familiar para mantenerlos funcionando. Los chicleros y caoberos que querian podian llevarse a su gente; las mujeres que iban con su marido le cocinaban, lavaban la ropa, sembraban hortalizas y criaban animales de corral; a los que estaban solos los atendia una cocinera que iba acompañada de dos o tres ayudantes, dependiendo del tamaño del campamento. Gracias a esta organización interna, varias "centrales" de hatos y de campamentos se convirtieron con el tiempo en poblaciones estables.

Los trabajadores, según Rosado Vega, no sólo se enfrentaban a la naturaleza en una lucha desigual, sino que además sufrían la explotación de capataces y contratistas, la falta de prestaciones como acceso a atención médica y el tener que comprar en las "tiendas de raya" de las compañias."

Ninguna de las personas entrevistadas habló alguna vez de dichas "tiendas de raya"; en la central de los campamentos habia "bodegas" pero donde los trabajadores compraban con libertad. Los contratistas y subcontratistas tenían la obligación de mantener surtidas esas tiendas, era común que las compañias fuesen dueñas

Ibidem. p. 132. 
de los barcos que hacian el recorrido Río Hondo-Payo Obispo y de las tiendas que importaban de Belice a Payo Obispo la mercancia necesaria, pero también existian dueños de barcos y tiendas que operaban en forma independiente y se encargaban de surtir a los pueblos de la ribera del Hondo.

Para contraponer lo que dice Rosado Vega de que no existían prestaciones para los trabajadores, está la costumbre de lo que se llamó el seven-eleven, que era una ración de carne, manteca, harina y café que los contratistas les daban por número de dias trabajados a la semana a cada chiclero. Esta ración se entregaba entera a quien hubiese laborado seis días y el trabajador indicaba si la ración se le entregaba a él en el campamento o a su familia si ésta se habia quedado en Payo Obispo. Lo mismo sucedía con el sueldo, el trabajador o su familia podian recibirlo por partes $o$ entero.

Rosado Vega describe la relación trabajadores-capataces-contratistas-companias, como una relación en la que lo único que le interesaba a la empresa eran sus ganancias y la explotación efectiva de los recursos, y a los trabajadores, que los seis meses que estaban en la selva pasaran pronto para poderse ir a emborrachar a Payo Obispo. No se puede negar que estas situaciones realmente existieron, eso no se pone en duda, pero lo que sí se puede cuestionar es el hecho de que Rosado Vega no ve en ningún momento de la novela la complejidad de las relaciones obrero-patronales.

Entre los trabajadores había especialistas para cada etapa del proceso productivo. La habilidad era algo que se valoraba y apreciaba, tanto fue asi, que existieron trabajadores a los cuales se les pagaba lo que pidiesen con tal de tenerlos laborando en el hato o en el campamento. Todo mundo se conocia, y si un trabajador adquiria fama de revoltoso o parrandero no lo contrataba nadie. Lo mismo sucedía con los contratistas, cosa que Rosado Vega ni menciona, si alguno adquiria fama de no pagar lo justo, de no dar prestaciones, de no tener surtida la tienda del hato y de ser mal patrón, era bien difícil que consiguiera trabajadores. Las noticias viajaban rápido en ambos sentidos.

En cuanto a la organización del trabajo, Rosado Vega la describe como si todos los chicleros se fueran juntos al monte y estando con su capataz, cada uno subia a su chicozapote. Esto no es cierto, los chicleros no compartían el área de explotación. Se escogían los árboles aptos para ser sangrados y se le indicaba a cada uno el área en que debía trabajar; algunas veces quedaban lejos del campamento central, al cual iban ya que tenian recolectados varios kilos de resina.

Todos estos elementos implican distintos grados de distorsión de la realidad social, distorsión que también está presente cuando habla de Payo Obispo y de las relaciones entre México y Belice. Payo Obispo es un antro de vicio donde los trabajadores, después de estar refundidos en la selva seis meses, van a emborracharse y a armar camorra. En Payo Obispo, el sitio donde se llevan a cabo buena parte de las acciones de la novela es la cantina La Consoladora, donde son tres los negocios principales: el agio, el alcohol y la prostitución.

En cuanto a los beliceños, lo único que pretendian era aprovecharse impunemente de las riquezas del suelo mexicano. Era ésta 
una región socio-económica donde el capital extranjero obtenía ganancias desmedidas gracias a la tremenda explotación de los trabajadores. Sería necio negar la existencia del lado oscuro de las cosas, pero sustentar esta posición maniquea como lo hace Rosado Vega, distorsiona la realidad histórico-social y nos indica un uso muy ideologizado de la ficción literaria.

Sólo resta situar cuándo se escribió la novela y la función ideológica que dentro de ese contexto histórico-social tuvo. Hemos visto que como fuente histórica no puede ser considerada, pero esto es en si un dato histórico concreto, lo mismo que los falseamientos de la realidad que en ella se encuentran. Así, la lectura de la novela y la relación que se estableció con la historia oral, aportó información vital para comprender el periodo cardenista en el Territorio.

El cardenismo es para Quintana Roo un parteaguas histórico, a partir de él se puede decir que la región comenzó a ser parte de México. Sus políticas, encaminadas a integrar esta parte del pais al todo nacional, modificaron sustancialmente la vida de Quintana Roo. Se enumerarán las más importantes, dando con esto el contexto histórico en que se escribió Claudio Martín.

La producción del chicle y de la madera se organizó en cooperativas de producción y consumo en las que los trabajadores vendían sin intermediarios su producción. Los compradores siguieron siendo las compañias inglesas y estadounidenses establecidas en Belice, pero las ganancias aumentaron para los trabajadores. Se sustituyó el grupo de capataces, contratistas y subcontratistas con una nueva burocracia.

Las relaciones fronterizas sufrieron modificaciones; se institucionalizó el uso de pasaportes para cruzar la frontera, se dio una búsqueda de los elementos "regionales mexicanos" con lo cual se sistematizó el rechazo a las relaciones culturales, económicas y sociales que existian entre Quintana Roo y Belice. Habia que hacer mexicana una región del país que nunca lo habia sido.

La primera política a este respecto fue cambiar de nombre a todas las poblaciones que lo tuvieran en inglés, les pusieron nombres de héroes nacionäles, regionales o en lengua maya, el caso más conocido es el cambio de Payo Obispo a Chetumal. Dentro de esta misma tónica está la creación de tradiciones y costumbres, como la "danza de los chicleros" y "el traje típico" de la chetumaleña.

Se construyeron caminos y pistas de aterrizaje con el propósito de integrar físicamente a la región. Esto fue el comienzo del fin de una forma de vida; Payo Obispo, de ser una ciudad-puerto que veía al mar, poco a poco le dio la espalda a la bahía y al rio. Los barcos de vela y vapor fueron sustituidos por aviones y coches.

Había que destruir toda la influencia de Belice en Payo Obispo, comenzando por el recordatorio más patente: el estilo arquitectónico. Se prohibió la construcción del old english colonial style, trajeron de Yucatán albañiles para que hicieran sólidas casas de mampostería siguiendo las líneas, a escala, del estilo colonial característico de la península yucateca.

Por último, otro elemento que caracterizó al cardenismo fue el rechazo constante y sistemático a los "extranjeros", que fueron los primeros pobladores de Payo Obispo. Esta ciudad se fundó (1898) 
con mestizos yucatecos que, huyendo de los horrores de la guerra de Castas, cruzaron al lado beliceño del Hondo y fundaron poblaciones como Corozal y Orange Walk; pero támbién una buena proporción de los primeros pobladores de Payo Obispo eran "ciudadanos del mundo": alemanes, griegos, libaneses, ingleses, cubanos, chinos, turcos, escoceses, etc., gente que llegó a Belice desde la primera mitad del siglo pasado y que al ofrecérseles tierras y posibilidades de trabajo, se pasaron al lado mexicano del Hondo.

Al mismo tiempo que se cuestionó la estancia de estos "extranjeros" que llevaban cerca de 40 años en Quintana Roo, se reivindicó a los cozumeleños como los "primeros pobladores" de Payo Obispo. Desde los años veinte hubo migraciones de la isla hacia la zona del Hondo. Tanto ellos como los yucateco-beliceños fueron declarados los "legítimos" pobladores "mexicanos" de la región.

Teniendo todo este contexto histórico-social en mente, se pueden entender los elementos ideológicos de la novela, con los cuales se sustenta la posición de que con el cardenismo se dio la "verdadera" revolución.

El "héroe" de la obra es cozumeleño, hecho significativo por todo el conflicto entre los mexicanos y los "extranjeros". El "villano", contratista seductor y explotador, es mitad yucateco y mitad "extranjero", por el apellido (Menéndez) se puede inferir que o viene del norte de Belice, o de Guatemala u Honduras.

Hay un rechazo constante a los beliceños y a sus "amos" ingleses y gringos, su opinión es que Belice fue "robado" a México, y por lo tanto las relaciones diplomáticas con los dos países son una farsa. A esto último se agrega el rechazo constante a la cultura compartida con Belice, para él la frontera no es algo que une, sino lo que rompe en dos una vida conjunta. Lo malo que llegaba a Payo Obispo venia de Belice: el contrabando, la prostitución, el alcohol, la magia negra, todo esto era tan malo como las razas que por ahi entraban.

Además de reivindicar a la Revolución, la novela concluye que México debe consolidarse como nación y ser sólo para los mexicanos. Había que integrar esta zona al resto del pais, había que definir la frontera, habia que introducir a México a una nueva etapa de desarrollo económico-social, todo esto significó para Quintana Roo, una nueva forma de vida. Ya era parte de la nación... 